\title{
Examining non-medical prescribing trends in New Zealand: 2016-2020
}

\author{
Rakhee Raghunandan * (D, Carlo A. Marra, June Tordoff(D) and Alesha Smith (D)
}

\begin{abstract}
Background: Population growth and general practitioner workforce constraints are creating increasing demand for health services in New Zealand (NZ) and internationally. Non-medical prescribing (NMP) is one strategy that has been introduced to help manage this. Little is known about the NMP practice trends in NZ. The aim of this study was to provide a current overview of the scale, scope, and trends of NMP practice in NZ.

Methods: All claims for community dispensed medicines prescribed by a non-medical prescriber were extracted from the NZ Pharmaceutical Collection for the period 2016-2020. Patient demographics were retrieved from the Primary Health Organisation enrolment collection. These national databases contain prescription information for all subsidised community pharmacy medicines dispensed and healthcare enrolment data for $96 \%$ of New Zealanders.

Results: The proportion of prescriptions written by all NMP providers and patients receiving NMP prescriptions increased each year from 1.8\% (2016) to 3.6\% (2019) and 8.4\% (2016) to 14.4\% (2019) respectively. From 2016 to 2019, the proportion of NMP patients who had at least one NMP prescription increased from $26 \%$ to $39 \%$ for nurse prescribers, from $1 \%$ to $9 \%$ for pharmacist prescribers, from $2 \%$ to $3 \%$ for dietitian prescribers, and decreased from $47 \%$ to $22 \%$ for dentists, and from $20 \%$ to $12 \%$ for midwives. The most commonly prescribed medicines were antibiotics (amoxicillin, amoxicillin with clavulanic acid, and metronidazole), and analgesics (paracetamol, and codeine phosphate). While some NMP providers were prescribing for patients with greater health needs, all NMP providers could be better utilised to reach more of these patients.
\end{abstract}

Conclusions: This study highlights that although the NMP service has been implemented in NZ, it has yet to become mainstream healthcare practice. This work provides a baseline to evaluate the NMP service moving forward and enable policy development. Improved implementation and integration of primary care NMP services can ensure continued access to prescribing services and medicines for our communities.

Keywords: Non-medical prescribing, Prescribing practice, Workforce, Healthcare, New Zealand

\section{Background}

As in other countries, non-medical prescribing (NMP) was introduced in New Zealand (NZ) to address the increased demand for healthcare services and diminishing access to prescribing services and medicines [1-3]. NMP is the legislative extension of prescribing rights to health professionals other than medical doctors, thereby enabling

\footnotetext{
* Correspondence: rakhee.raghunandan@postgrad.otago.ac.nz School of Pharmacy, University of Otago, PO Box 56, Dunedin, Otago 9054, New Zealand
}

them to prescribe medicines classified as prescription medicines, and facilitate timely access to medicines [4]. This is particularly significant as $49 \%$ of general practitioners (GPs) in NZ work part time and 47\% of GPs intend to retire from general practice in the next 10 years [5]. The inequity of access to medicines in primary care in NZ is well documented and includes issues such as physical and timely access to a prescriber/prescription, and the direct and indirect costs associated with consulting a prescriber [6]. 
NMP is still a relatively new practice in NZ and is changing significantly with the number of non-medical health professional groups gaining prescribing rights increasing. NZ non-medical prescribers include dentists, midwives, nurse prescribers (nurse practitioners and registered nurse prescribers), pharmacist prescribers, optometrists and dietitian prescribers [7]. In NZ dentists, nurse practitioners, midwives, and optometrists prescribe independently without a medical prescriber, while pharmacist prescribers, registered nurse prescribers, and dietitian prescribers all prescribe collaboratively with the involvement of a medical prescriber [7]. There is some NZ research examining the rates of NMP in NZ [8], and the prescribing practice of nurse practitioners [9-11] and dentists [12]. There is paucity of research that encompasses all NMP and current research is very profession-specific. Little is known about the current utilisation of NMP services and the prescribing practice of all non-medical prescribers in NZ. Eliciting this type of information will help describe the current impact/ contribution of NMP in primary care NZ, and can contribute to workforce development to enable efficient and sustainable NMP services in NZ.

This study aims to provide a current overview of nonmedical prescribers' prescribing trends in NZ with specific objectives to determine the:

- contribution and trends of all non-medical prescribing to overall prescribing from 2016 to 2020;

- contribution and trends of each NMP health professional group to all non-medical prescribing from 2016 to 2020;

- demographics of patients who receive prescriptions from non-medical prescribers;

- most frequently prescribed therapeutic groups and medicines by non-medical prescribers.

\section{Methods}

Study design

This retrospective nationwide observational study used the NZ Ministry of Health Pharmaceutical Collection and the Primary Health Organisation (PHO) Enrolment databases $[13,14]$. These databases capture $96 \%$ of all New Zealanders, as approximately $4 \%$ of the NZ population are not enrolled at a primary care practice [15] and are not captured in these two databases.

Medicines and therapeutic products that are publicly funded in NZ are listed in the NZ Pharmaceutical Schedule (community and hospital schedules), which is managed by the Pharmaceutical Management Agency, PHARMAC [16]. PHARMAC is an independent statutory organisation responsible directly to the NZ Minister of Health and works with the Ministry of Health [17]. PHAR MAC determines which medicines and therapeutic products will be fully and/or partly subsidised by public funding in NZ [18]. The Pharmaceutical Collection, which is jointly owned by the Ministry of Health and PHARMAC, is a data warehouse that records the claims submitted by all pharmacies in NZ for the reimbursement of the subsidised medicines that have been dispensed to all patients [19]. The PHO Enrolment Collection is a national database that holds primary care patient enrolment data [20].

The Pharmaceutical Collection was searched between 1 January 2016 to 30 June 2020 (4.5 years) using the distinct provider type codes to identify dispensed medicines prescribed by: dentists, nurse prescribers (which includes nurse practitioners and registered nurse prescribers), optometrists, midwives, pharmacist prescribers, and dietitian prescribers. The number of distinct enrolled patients who were dispensed a medicine from a NMP and the number of original prescriptions dispensed were also determined. The distinct original prescription dispensing refers to each single item prescribed by a prescriber on a prescription form to a patient, and does not include any repeat dispensing that occurred from a prescription. The distinct patients were identified using the encrypted National Health Index (NHI) number, which is unique for each patient and remains the same in each healthrelated database across a patient's lifetime and allows the linking of collections. The following patient sociodemographic details were also retrieved from the PHO Enrolment Collection: age, gender, ethnicity, NZ Deprivation Index (NZDep2013 score), and District Health Board (DHB) provider. Data for the 100 most dispensed medicines by therapeutic group and medicine chemical name (as listed in the community Pharmaceutical Schedule) [16] for overall NMP and each NMP provider were also retrieved from the Pharmaceutical Collection.

\section{Analysis}

Descriptive statistical analyses, using Excel $2016^{\circ}$, were conducted on the aggregated data set, to determine NMP contribution to overall community dispensed medicines in NZ, NMP by non-medical prescriber provider type (e.g. nurse prescriber, dentist, etc.), the demographics of the patients who received prescriptions from nonmedical prescribers, and summarise the types of medicines prescribed by non-medical prescribers in NZ.

The study analysed patients' DHB, deprivation and self-reported ethnicity data. The following Statistics New Zealand reporting standards for ethnicity were used: Asian, Māori, MELAA (defined as Middle Eastern, Latin American, and African), NZ European/European, Other, and Pacific Peoples. The NZDep2013 score combines census data relating to income, home ownership, employment, qualifications, family structure, housing, access to transport and communications [21]. The NZDep2013 index groups deprivation scores into deciles, where 1 
represents the areas with the least deprived scores and 10 the areas with the most deprived scores [21]. DHB rural populations were identified from a Ministry of Health commissioned report [22]. DHBs were categorised as 'rural' if they had a greater than $20 \%$ rural population.

\section{Results}

This study was approved by the University of Otago Human Ethics Committee (reference HD20/029).

\section{NMP and non-medical prescriber providers}

The number of dispensed prescriptions written by all healthcare prescribers (medical and non-medical) increased by $10.8 \%$ from 2016 to 2019 (78,056,369 prescriptions vs $86,514,345)$. The number of patients who had a prescription issued by all healthcare prescribers (medical and non-medical) increased by $4.7 \%$ from 2016 to $2019(3,356,850$ vs $3,514,106)$ (Table 1$)$. The number of medical prescriptions dispensed also increased from 2016 to 2019 (76,476,931 vs 83,227,282).

The annual proportion of NMP prescriptions for all prescriptions dispensed and NMP patients for all patients dispensed to, has increased over the past 4 years (i.e. $1.8 \%$ in 2016 to $3.6 \%$ in 2019 for NMP prescriptions and $8.4 \%$ in 2016 to $14.4 \%$ in 2019 for NMP patients respectively) (Table 1), but not at the same rates for all prescribing (i.e. increases of $10.8 \%$ for prescriptions and $4.7 \%$ for patients).

Nurse prescribers were the largest NMP contributors $(1.40 \%)$ to all prescriptions (medical and non-medical) dispensed between 2016 and 2020, followed by dentists $(0.64 \%)$, midwives $(0.39 \%)$, and pharmacist prescribers (0.25\%). Optometrists and dietitian prescribers were the smallest contributors equally $(0.06 \%)$. Nurse prescribers increased their proportion of all NMP prescriptions from 35\% (2016) to 56\% (2019), and they contributed $50 \%$ of all NMP prescriptions for the four-and-a-halfyear period (2016-2020) (Fig. 1). Dentists had the largest proportion of NMP prescriptions in 2016 (36\%) and the second largest (although decreasing) in 2019 (18\%), and by mid- 2020 this was $14 \%$. Pharmacist prescribers' contributions increased from $2 \%$ in 2016 to $11 \%$ in 2019 , and contributed $9 \%$ of all NMP prescriptions for the four-and-a-half-year period (2016-2020).

\section{Patients}

Nurse and pharmacist prescribers were prescribing for an increasing proportion of NMP patients from 2016 to 2019 (Fig. 2). Nurse prescribers prescribed for 36\% of all NMP patients and pharmacist prescribers prescribed for $10 \%$ of all NMP patients for the four-and-a-half-year period (2016-2020). From 2016 to 2020, 47-22\% of NMP patients had prescriptions from dentists; $20-12 \%$ from midwives; $4-3 \%$ from opticians; and $2-3 \%$ from dietitians.

Table 2 presents the sociodemographic characteristics of the patients who had a NMP prescription dispensed between 1 January 2016-30 June 2020, and summarises these findings in terms of each specific non-medical provider type and NMP providers overall. Individual patients may have received a prescription from multiple NMP and medical providers (e.g. dentist, midwife, and GP). Hence, the number of original prescriptions and/or number of patients differs for many categories in the analyses.

While the majority of patients seen by NMP providers were female $(60.9 \%)$, dentists and dietitian prescribers prescribed for almost equal proportions of female and male patients (Table 2). During the period 2016-2020, the median age for the NMP patients was 39 years (IQR 25-61 years). The youngest patients were seen by midwives (median $=29$, IQR 24-33), followed by nurse prescribers (median $=36$, IQR 19-40), and dentists ( median $=48$, IQR 30-62). The patients' median age was $57-60$ years for optometrists (median $=57$, IQR 38-71),

Table 1 Summary of NZ NMP by number of original prescriptions dispensed and patients from 2016 to 2020

\begin{tabular}{|c|c|c|c|c|c|c|c|c|}
\hline Calendar year & $\begin{array}{l}\text { Medical } \\
\text { prescriptions } \\
\text { dispensed }\end{array}$ & $\begin{array}{l}\text { NMP } \\
\text { prescriptions } \\
\text { dispensed }\end{array}$ & $\begin{array}{l}\text { All } \\
\text { (medical }^{\text {and NMP) }} \\
\text { prescriptions } \\
\text { dispensed }^{\mathrm{a}}\end{array}$ & $\begin{array}{l}\text { NMP } \\
\text { prescriptions } \\
\text { as \% of all } \\
\text { prescriptions }\end{array}$ & $\begin{array}{l}\text { Medical } \\
\text { patients } \\
\text { dispensed to }\end{array}$ & $\begin{array}{l}\text { NMP } \\
\text { patients } \\
\text { dispensed to }\end{array}$ & $\begin{array}{l}\text { All (medical and } \\
\text { NMP) patients } \\
\text { dispensed to }\end{array}$ & $\begin{array}{l}\text { NMP patients as } \\
\% \text { of all patients } \\
\text { dispensed to }\end{array}$ \\
\hline 2016 & $76,476,931$ & $1,407,028$ & $78,056,369$ & $1.8 \%$ & $3,318,498$ & 282,841 & $3,356,850$ & $8.4 \%$ \\
\hline 2017 & $81,006,690$ & $1,851,714$ & $83,023,775$ & $2.2 \%$ & $3,432,519$ & 347,441 & $3,477,274$ & $10.0 \%$ \\
\hline 2018 & $84,263,278$ & $2,610,400$ & $87,075,543$ & $3.0 \%$ & $3,482,168$ & 445,528 & $3,538,311$ & $12.6 \%$ \\
\hline 2019 & $83,227,282$ & $3,101,161$ & $86,514,345$ & $3.6 \%$ & $3,450,211$ & 506,945 & $3,514,106$ & $14.4 \%$ \\
\hline $\begin{array}{l}2020 \text { half year } \\
\text { (1st Jan-30th } \\
\text { June) }\end{array}$ & $33,163,443$ & $1,304,021$ & $34,535,777$ & $3.8 \%$ & $2,574,434$ & 239,478 & $2,641,302$ & $9.1 \%$ \\
\hline 2016-2020 & $358,137,624$ & $10,274,324$ & $369,205,809$ & $2.8 \%$ & $16,257,830$ & $1,822,233$ & $16,527,843$ & $11.0 \%$ \\
\hline
\end{tabular}

$\mathbf{a}=$ totals may not sum the Medical and NMP columns due to patients getting a prescription from more than one prescriber (i.e. medical and NMP providers) and/ or data classification error in databases 


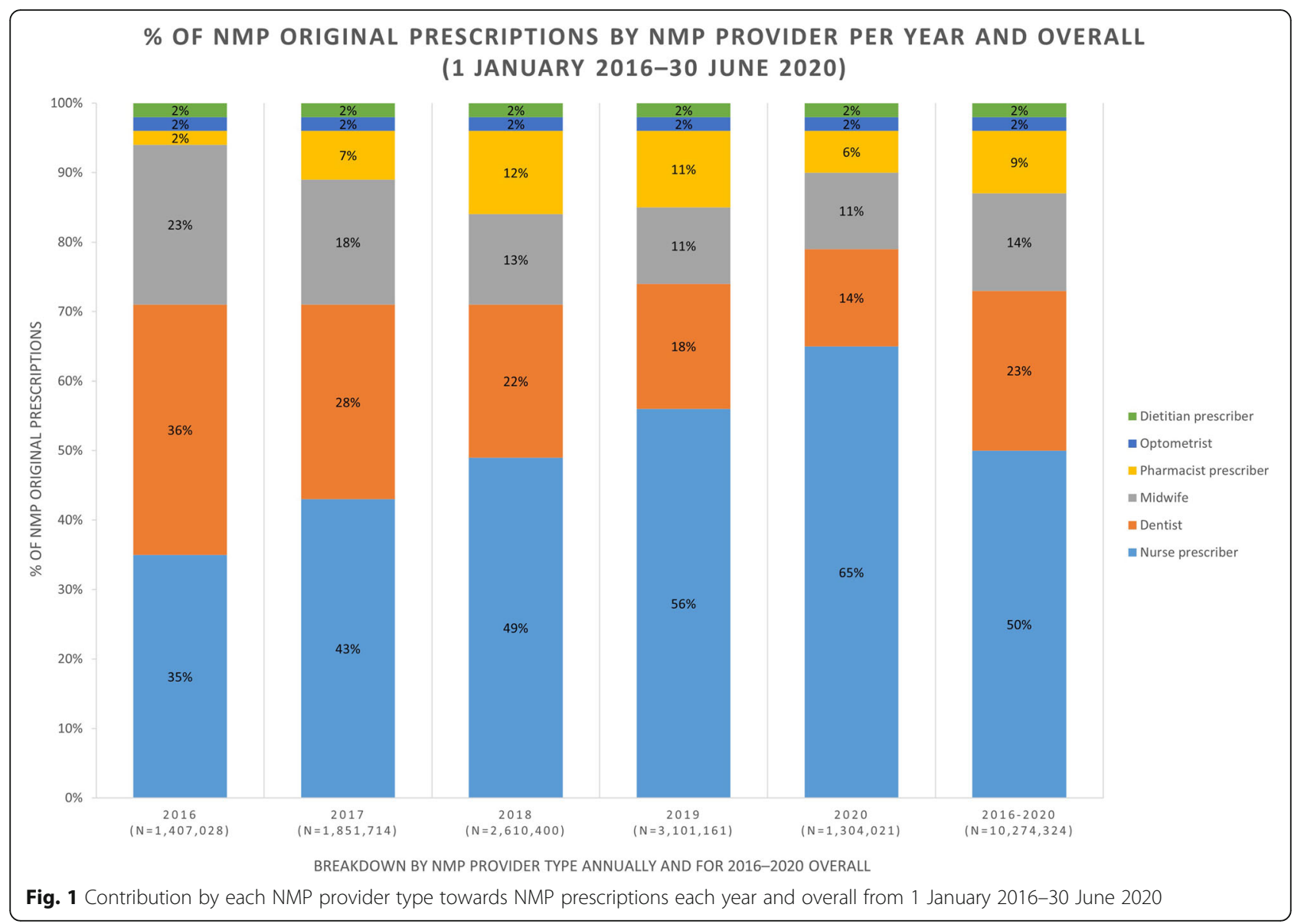

pharmacist prescribers $($ median $=59$, IQR $31-72)$, and dietitian prescribers (median $=60$, IQR 20-76).

The NZDep2013 score was recorded for 1,017,132 NMP patients with a median score of 6 (IQR 3-8). In total, 466,393 NMP patients (42.8\%) were living in the more deprived areas (i.e. NZDep2013 decile 7-8 and above). During 2016-2020, optometrists saw patients living in the less deprived areas (NZDep2013 median score $=5, I Q R ~ 2-7)$ and nurse prescribers saw patients living in more deprived areas (NZDep2013 median score = 7, IQR 4-9).

For all NMP providers overall, 171,882 (15.8\%) patients self-identified as Māori and 54,011 (5.0\%) as Pacific peoples. Nurse prescribers prescribed for the highest proportion of Māori patients (83,756 (21.6\%)) and optometrists for the lowest proportion of Māori patients $(2676(5.8 \%))$. Midwives prescribed for the highest proportion of Pacific patients $(11,309(6.6 \%))$ and optometrist prescribers prescribed for the lowest proportion of Pacific patients (1284 (2.8\%)). Twelve percent of pharmacist prescribers' patients self-identified as Māori and $3.5 \%$ as Pacific.

The five DHBs with the most patients receiving a prescription from a NMP provider were: Counties Manukau
(117,157 patients $(10.3 \%))$, Waitematā $(116,849(10.3 \%))$, Canterbury (115,353 (10.1\%)), Waikato DHB (113,218 (10.0\%)), and Auckland (103,098 (9.1\%)). Most rural DHBs had lower numbers of NMP patients (e.g. Wairarapa 17, 246 (1.5\%) and South Canterbury 12,500 (1.1\%)), and included the two DHBs with the least NMP patients which were West Coast $(9227(0.8 \%))$ and Tairāwhiti $(10,865$ $(1.0 \%))$.

\section{Prescriptions}

Based on the 100 most frequently prescribed therapeutic groups by NMP providers, we ascertained the top five therapeutic products that were most prescribed by NMP providers during the period from 1 January 2016-30 June 2020. For all NMP providers, the two most frequently prescribed therapeutic groups were antibacterials with 1,802,812 dispensings (23.4\%), followed by analgesics $(1,096,706(14.3 \%))$. Antibacterials were also the most prescribed therapeutic group by dentists (1, $263,218(53.8 \%))$, and the second most prescribed therapeutic group by nurse prescribers $(432,657(8.4 \%))$ and optometrists $(5320(2.5 \%))$. Analgesics were the most prescribed therapeutic group by nurse prescribers (534, $387(10.4 \%))$, and the second most prescribed 


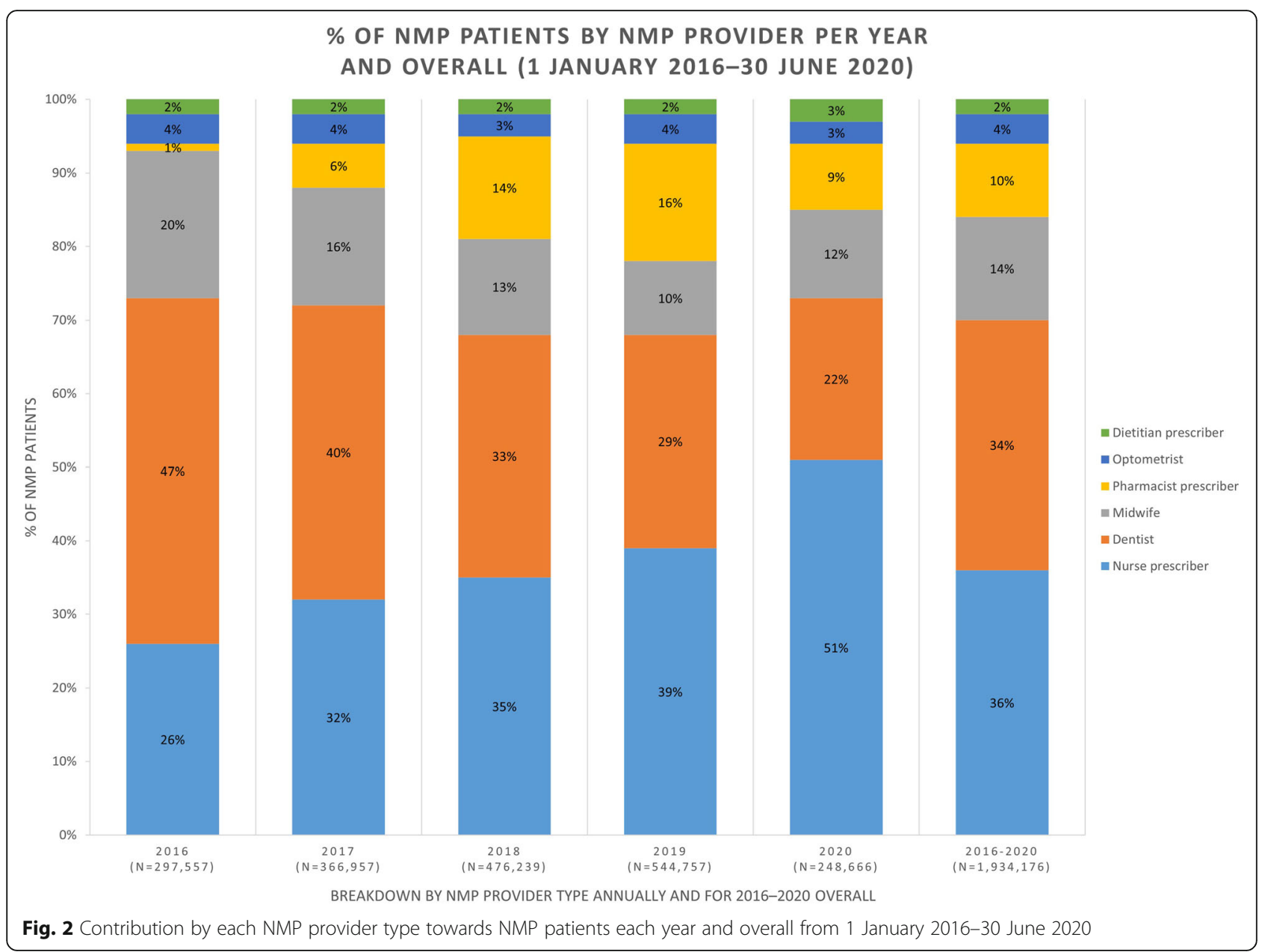

therapeutic group by dentists $(418,768(17.8 \%))$ and midwives $(115,852(7.7 \%))$. The analgesic therapeutic group included medicines such as paracetamol, codeine phosphate, and tramadol, but excluded ibuprofen and diclofenac, which are categorised as non-steroidal antiinflammatory agents in the Pharmaceutical Collection data.

The top five most prescribed therapeutic groups by pharmacist prescribers were contraceptives-hormonal with 159,013 dispensings (17.9\%), followed by vaccinations $(128,332(14.4 \%))$, treatments for substance dependence $(113,378(12.7 \%))$, lipid-modifying agents (38, 199, (4.3\%)), and agents affecting the renin-angiotensin system $(37,353(4.2 \%))$. Unsurprisingly, the eye preparation therapeutic group was most prescribed by optometrists $(95.6 \%)$, and all the top five therapeutic groups prescribed by dietitian prescribers related to nutrition.

Based on the 100 most frequently prescribed medicines by NMP providers, Table 3 presents the top ten medicines prescribed during the study period. For all NMP providers, the most frequently prescribed medicine was amoxicillin (902,786 dispensings, 17.5\%), followed by paracetamol $(617,500(12.0 \%))$, and amoxicillin with clavulanic acid (458,519 (8.9\%)). Amoxicillin was most prescribed medicine by dentists (737,840 dispensings, $32.6 \%)$, and the third most prescribed medicine by nurse prescribers $(140,754(6.2 \%))$. Paracetamol was the most prescribed medicine by nurse prescribers (362,511 $(15.8 \%))$, and featured in the top ten medicines prescribed by dentists, midwives and pharmacist prescribers. Compared with the top ten medicines prescribed by dentists and nurses, pharmacist prescribers were prescribing more medicines associated with long term conditions (i.e. atorvastatin, metoprolol succinate, omeprazole, aspirin, salbutamol, and metformin).

\section{Discussion}

\section{Summary of findings}

This study reported the first data describing all NMP in New Zealand providing an important baseline for future comparisons. The increasing contribution trend of nurse prescribers towards NZ NMP could be due to their new 'registered nurse prescriber' scopes of practice [23], a supportive regulatory authority, and streamlined education 


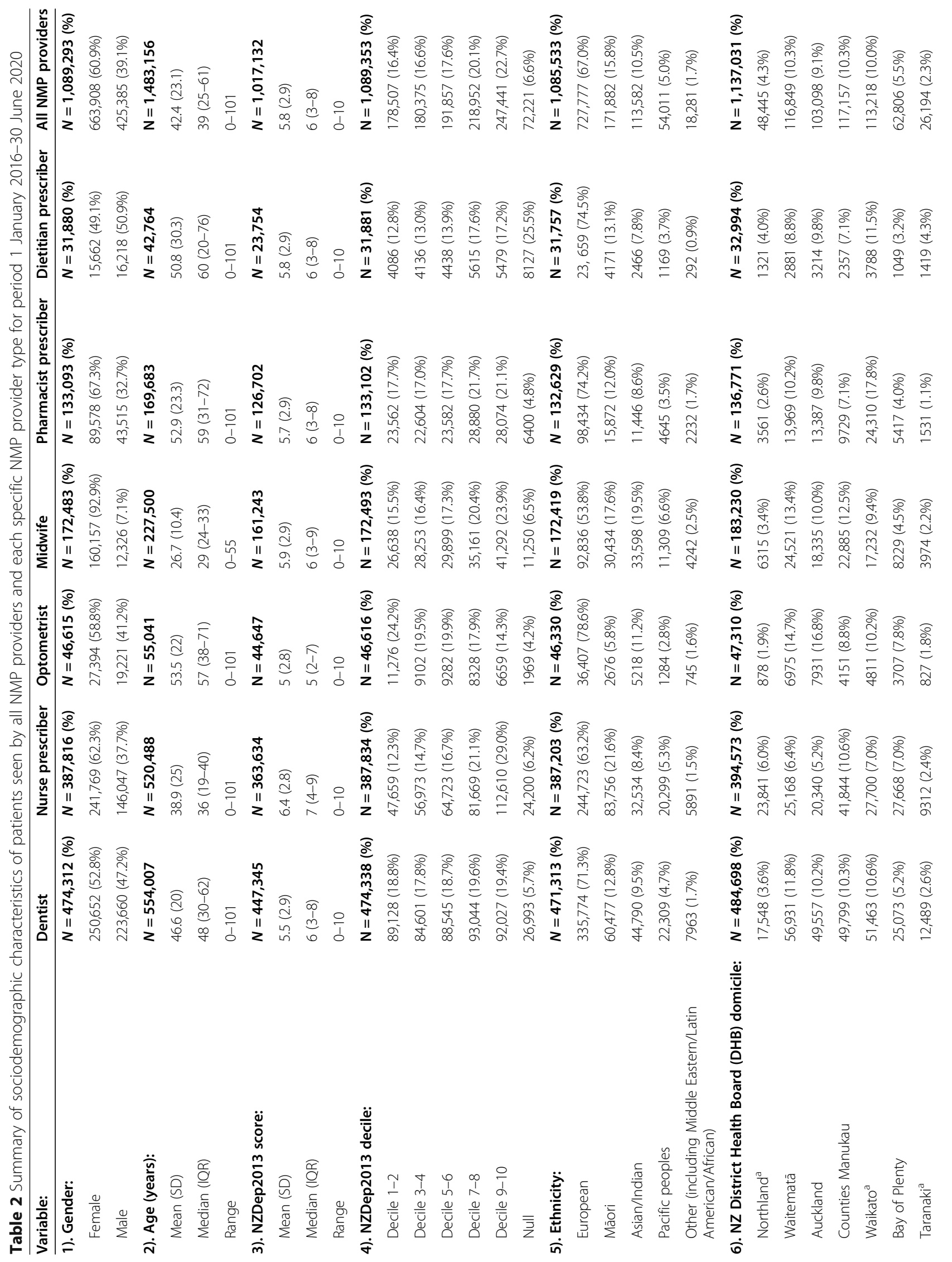




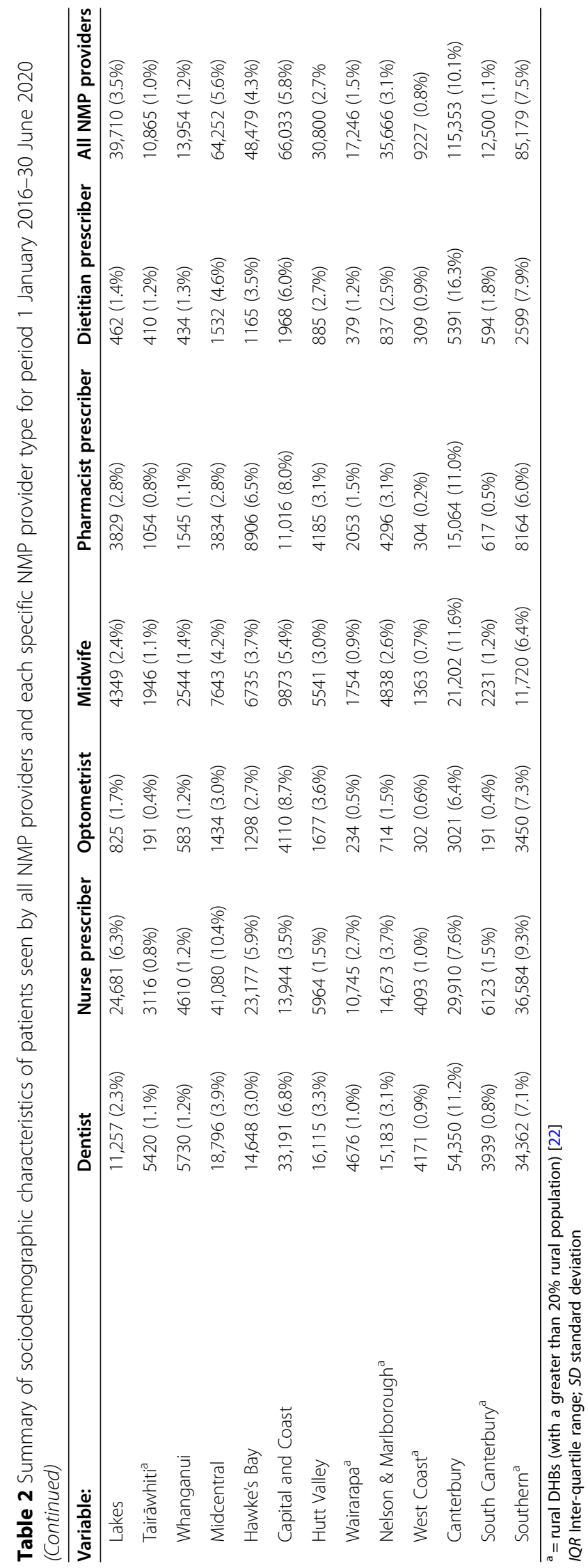




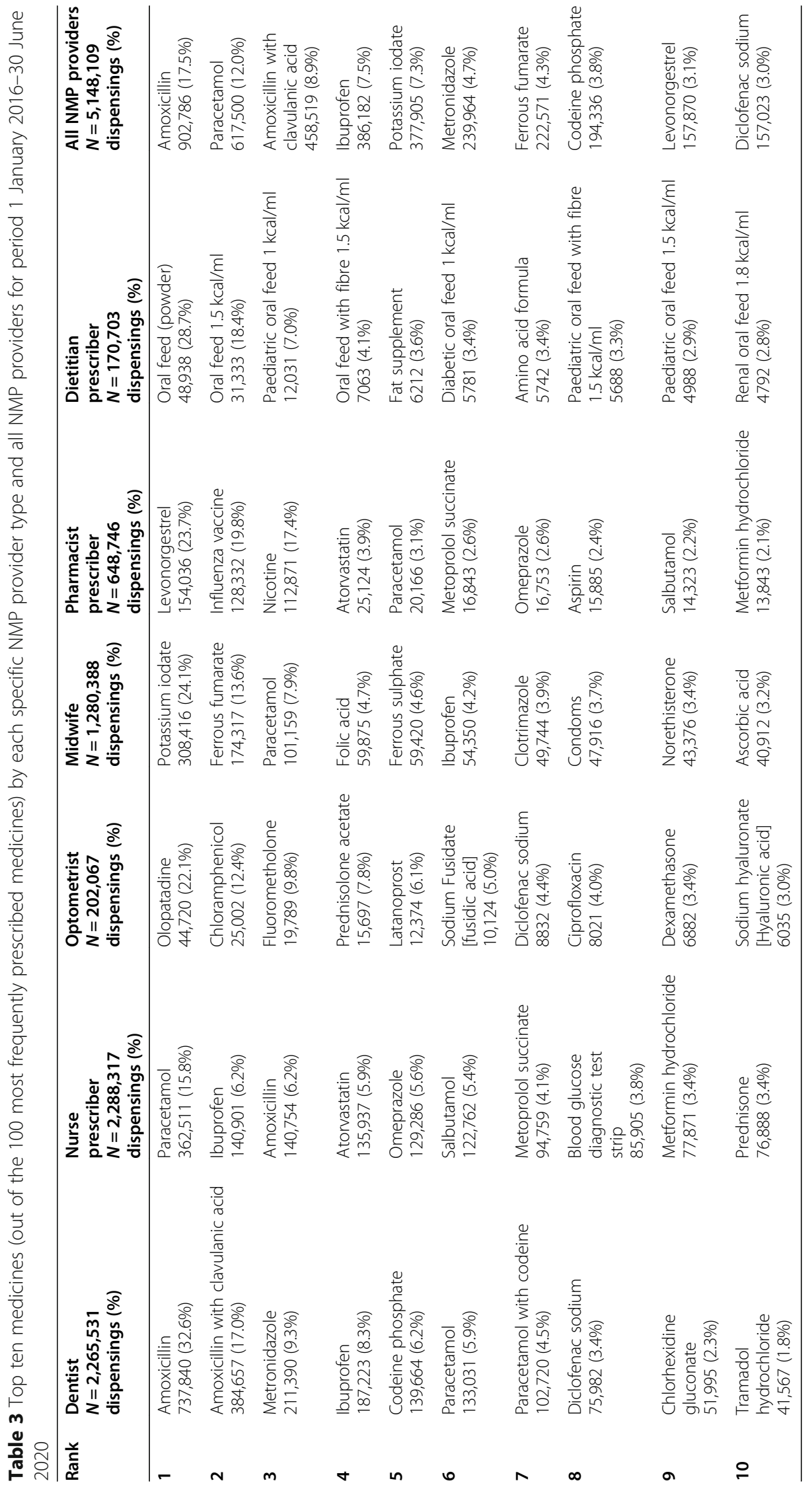


programmes, allowing increasing numbers of nurses prescribers (nurse practitioners and registered nurse prescribers) to prescribe in practice in NZ [24]. As New Zealanders make more use of some of the long-standing and new NMP providers such as nurse prescribers, the proportion of contributions towards NMP by some NMP providers such as dentists and midwives has decreased to some extent.

Only nurse prescribers and midwives prescribed for a higher proportion of Māori patients (21.6\% and 17.6\% respectively) than in the general New Zealand population (16.5\%) [25]. However, overall it would appear that NMP providers were not providing healthcare to all communities with greater health needs, for example NMP providers prescribed for a lower proportion of patients of Pacific ethnicity than found in the general New Zealand population (8.1\%) [25]. Midwives and nurse prescribers prescribed for a younger cohort of patients in NZ, with patient median ages (29 and 36 years respectively), slightly below the NZ national median age of 37.4 years [26].

Antibacterials and analgesics (including non-steroidal anti-inflammatory agents) were, on average, the most prescribed therapeutic groups by NMP providers. These two therapeutic groups were also in the top five groups prescribed by NZ GPs in the most recent statistics (2018) [27]. There is a lot of similarity in the top ten most prescribed medicines by NMP providers in this study and by GPs [27]. For example, amoxicillin and amoxicillin with clavulanic acid which ranked highly in NMP also featured in the top twenty most prescribed medicines by GPs [27]. The analgesics (including paracetamol, paracetamol with codeine, codeine, ibuprofen, diclofenac, and tramadol hydrochloride), featured in the top ten medicines prescribed by all NZ NMP providers overall, and all prescribers except dietitian prescribers. In contrast, paracetamol and ibuprofen were the only analgesics in the top twenty most prescribed medicines by GPs [27]. However, opioids may be lower on the list of most prescribed by GPs as they have a wider range of patients/conditions to treat. NZ data indicates that codeine and tramadol were the two most prescribed opioids between 2013 and 2017, with tramadol use increasing by $13 \%$ [28].

\section{Comparison with existing literature}

It is difficult to compare the prescribing practice of the NZ NMP providers in this study as there a scarcity of published work about NMP providers' practice in NZ and internationally. The number of original prescriptions written by non-medical prescribers in NZ is increasing and has surpassed the 1 million NMP prescriptions reported in earlier NZ research [8], with this study reporting 1,407,028 NMP prescriptions in 2016 and more than doubling to $3,101,161$ NMP prescriptions by 2019.

Similar to NZ, UK research reported that nurse prescribers are the biggest contributor to NMP prescriptions in the UK, however UK nurse prescribers accounted for a much higher proportion (94.4\%) of NMP prescriptions dispensed in primary care $(93,102$, 682 out of $98,577,980$ NMP prescriptions) for the 5 year period January 2011-December 2015 [29]. It is noted that in the UK, midwives are regulated by the Nursing and Midwifery Council UK and their prescribing is captured within nurse prescribing [30].

While pharmacist prescribers contributed modestly $(0.25 \%)$ to all NZ prescribing, they were the fourth largest contributors to NMP prescriptions $(9.0 \%)$ from 2016 to 2020 (Fig. 1), with a high of $12 \%$ in 2018. In contrast, pharmacist prescribers in the UK are the second largest contributor to NMP prescriptions in primary care producing $5.5 \%$ of all NMP prescriptions dispensed during January 2011-December 2015 [29]. While the UK percentage is smaller than that of pharmacist prescribers in NZ, the number of NMP prescriptions written by pharmacist prescribers is much higher in the UK (i.e. 5,454,942 out of 98,577,980 NMP prescriptions from 2011 to 2015) [29], than in NZ (i.e. 890,444 out of 10, 274,324 NMP prescriptions from 2016 to 2020). Pharmacist prescribers in both countries have the potential to contribute more to NMP and overall prescribing in primary care.

There is only one existing NZ study about NMP practice with which this present study can be compared (Poot et al), however, that study only focused on nurse practitioner prescribing practice [10]. This present study's nurse prescribers' patient cohort is younger than seen in Poot et al's study (median age $=40$ years) [10]. One reason could be the broad practice scope of nurse practitioners compared to the primary care focus of the registered nurse prescribers. Poot et al found that nurse practitioners were prescribing for patients living in areas of more deprivation, to a higher proportion of Māori patients, and a lower proportion of Pacific people [10], which was similar to patient cohort findings for the nurse prescribers in the present study.

NZ research found three antibiotics (amoxicillin, amoxicillin with clavulanic acid, and flucloxacillin) in the top ten most prescribed medicines by nurse practitioners in 2013-2015 [10]. UK research also confirms that penicillins, which include amoxicillin and amoxicillin with clavulanic acid, are the most prescribed antibacterial class for all NMPs overall, and nurse and pharmacist prescribers [29]. Given the increasing issue of antimicrobial resistance, further examination around the appropriateness of this prescribing is warranted as 
this is largely unknown. Earlier NZ research evaluating antibiotic prescribing found that generally NZ dentists followed clinical guidelines [12], however recent Australian research concluded the overuse of antibiotics by Australian dentists for both therapeutic and non-therapeutic reasons [31]. This Australian research also found that a small proportion of general dentists prescribed diclofenac, codeine, and tramadol, which were considered inappropriate analgesics according to their Australian oral and dental therapeutic guidelines [31]. While there are no specific dentist guidelines in NZ for prescribing analgesics, this present NMP study found that NZ dentists were prescribing diclofenac, codeine, and tramadol which were considered inappropriate analgesics according to Australian guidelines.

\section{Implications for policy and practice in NZ}

The larger urban DHBs account for $48.3 \%$ of NZ NMP patients as they have bigger population bases. Based on current prescribing practice of the overall NMP service, there is a great opportunity for NZ NMP providers, including pharmacist prescribers, to contribute to communities with greater health needs, including Māori and Pacific communities [32, 33]. Rural NZ struggles with adequate workforce and inequity of access to healthcare [34], and rural DHBs often have higher proportions of patients who experience an unmet need for primary healthcare (e.g. a higher proportion of Māori and Pacific patients) [35]. While it is acknowledged that the rural DHBs account for smaller proportions of all NMP patients in this study due to their smaller population bases, NMP services could be further utilised to reach communities who are experiencing unmet primary healthcare needs in rural NZ.

The high prescribing of analgesics and antibiotics by non-medical prescribers suggest that they are dealing with a high number of acute conditions. These examples could signal that non-medical prescribers are prescribing within their scope such as dentists treating oral/dental infections and conditions that required pain relief. It also suggests that non-medical prescribers could be taking some of the burden from GPs and be helping to improve medicines access equity for acute conditions. UK research has indicated that NMP has made better use of health professionals' skills (including nurse and pharmacist independent prescribers) to reduce workload pressures of GPs [36-38].

NZ pharmacist prescribers prescribed more preventative agents (nicotine replacement therapy), and immunisations (influenza vaccine). UK pharmacists are also increasingly prescribing the influenza vaccine [39] and in 2018, pharmacists in Canada also delivered 34\% of adult influenza doses [40]. The current uptake of NZ pharmacist prescribers for preventative agents demonstrates that they could be further utilised to prescribe preventative agents, including a wider range of funded immunisations in NZ. Older people (65 years and over) make up 15\% of the NZ population, use $42 \%$ of health services, and over the last 10 years spending on services for older people is increasing faster than other expenses [41] Current NZ pharmacist prescriber practice indicates that they prescribe more medicines for long term conditions and for a higher proportion of older patients. NZ pharmacist prescribing services could be improved in primary care to help manage the increasing prescribing burden associated with long term conditions and an aging population. Canadian research has demonstrated the value of pharmacist prescribing services to manage long term conditions such as hypertension and cardiovascular risk $[42,43]$, which increase in prevalence as people age.

Understanding NMP practice in NZ identifies areas that require sufficient initial and continuing education. $\mathrm{NZ}$ is a relatively high user of antibiotics [44, 45], and overuse of antibiotics is a key factor [46, 47] in the global health problem of antibiotic resistance $[48,49]$. Identifying that antibiotics are commonly prescribed by NMPs suggests that further research is required to evaluate the appropriateness of this prescribing. It also highlights the need for adequate education about antimicrobial stewardship to ensure that NMPs are not contributing to antibiotic resistance [50]. Appropriate analgesic prescribing is also important, especially with the concerns internationally about rising prescription opioid use and misuse [51]. Prescribers need to be fully aware of opioid-related risks and adverse effects, as well as the potential for opioid misuse [52-54] while optimising pain relief for patients.

\section{Strengths and limitations}

A strength of this study is the large data set available for analysis, with dispensing, prescriber, patient, and medicines details. The data set contained comprehensive sociodemographic details for each patient and captures $>96 \%$ of the New Zealand population. It is acknowledged that dispensing may not fully reflect prescribing, as patients who had a prescription issued but did not take it to a pharmacy for dispensing, are not captured in this study. The Pharmaceutical Collection data did not differentiate between pharmacists prescribing funded medicines as registered pharmacist prescribers and via the pharmacist only medicines classification. This study captured both nurse practitioner and registered nurse prescribing within the 'nurse prescribing' umbrella term.

\section{Conclusions}

All the NMP professions in NZ appear to be prescribing medicines within their usual practice. While there is modest growth in this service, NZ NMP still makes very small contributions to overall prescribing in primary 
care. Nurse prescribers are the largest contributor to NMP, and other NMP providers including pharmacist prescribers have the potential to contribute more to this service.

There is some indication that NMP providers could be alleviating the prescribing burden on GPs and improving access by prescribing for acute conditions that require pain relief or antibiotics. However, overall all NMP providers could be better utilised to provide prescribing services to our communities with greater health needs and improve access to these healthcare services. NMP providers have the potential to improve healthcare service delivery to cope with unmet health needs in rural NZ, a sector that struggles to meet health needs due to workforce constraints and inequity of access. The variation of NMP service provision across the different DHBs in NZ indicates that the NMP service has been well integrated in certain geographic areas, and this variation could be due to better support and funding in some DHBs compared to others. This study highlights the importance of identifying what medicines NMP providers are prescribing, to ensure adequate education and continuing professional development to support best practice and appropriate prescribing decisions. Further research is needed to determine the impact of NMP on patient outcomes and access to healthcare.

As NZ seeks to cope with the increasing demand for health services, factors such as workforce constraints have the potential to affect the availability of the usual GP prescriber in primary care. NZ has to make better use of the skills of other health professionals, and must consider new models of care and service delivery to meet these increasing healthcare needs. This study highlights that NMP has been implemented in NZ, but it has not yet become mainstream healthcare practice. This work provides a baseline to evaluate the NMP service moving forward and contribute to policy development. Improved implementation and integration of primary care NMP services can enable continued access and reduce inequity to prescribing services and medicines for our communities.

\section{Abbreviations \\ DHB: District Health Board; GP: General practitioner; GPs: General practitioners; IQR: Inter-quartile range; MELAA: Middle Eastern, Latin American, and African; NMP: Non-medical prescribing; NHI: National Health Index; NZ: New Zealand; NZDep2013: New Zealand Deprivation Index 2013; PHO: Primary Health Organisation; SD: Standard deviation; UK: United Kingdom}

\section{Acknowledgments}

N/A

\section{Authors' contributions}

AS retrieved and aggregated the data. RR performed the analyses with supervision from AS. AS, CM and JT supervised the project, providing overall direction and planning. All authors contributed to the final manuscript by providing critical feedback and helping shape the research, analysis and writing of the manuscript. The author(s) read and approved the final manuscript.

\section{Funding}

This research was undertaken with the aid of a $\mathrm{PhD}$ scholarship from the University of Otago, New Zealand. The University of Otago had no role in the design and conduct of the study; collection, management, analysis, and interpretation of the data; preparation, review, or approval of the manuscript; and decision to submit the manuscript for publication.

Availability of data and materials

The data sets generated and analysed during this study are not publicly available due to constraints imposed in the Ethics process, but are available from the corresponding author on reasonable request subject to approval.

\section{Declarations}

Ethics approval and consent to participate

This study was approved by the University of Otago Human Ethics Committee (reference HD20/029). All methods were carried out in accordance with relevant guidelines and regulations. The National Ethics Advisory Committee's Ethical Guidelines (NEAC Guidelines) permits the reuse of this de-identified health data for research with a consent waiver.

\section{Consent for publication}

Not applicable.

\section{Competing interests}

The authors declare no conflicts of interest or competing interests.

Received: 4 December 2020 Accepted: 5 April 2021

Published online: 03 May 2021

\section{References}

1. Department of Health. Prescribing by Non-Medical Healthcare Professionals. United Kingdom. 2016. https://www.health-ni.gov.uk/articles/pharmaceutica I-non-medical-prescribing. Accessed 16 Feb 2016.

2. Cope LC, Abuzour AS, Tully MP. Nonmedical prescribing: where are we now? Ther Adv Drug Saf. 2016;7(4):165-72. https://doi.org/10.1177/2042 098616646726.

3. Ecker S, Joshi R, Shanthosh J, Ma C, Webster R. Non-Medical prescribing policies: A global scoping review. Health policy (Amsterdam, Netherlands). 2020;124(7):721-6. doi:https://doi.org/10.1016/j.healthpol.2020.04.015.

4. Raghunandan R, Howard K, Marra CA, Tordoff J, Smith A. Identifying community pharmacist preferences for prescribing Services in Primary Care in New Zealand: a discrete choice experiment. Appl Health Econ Health Policy. 2020;19(2):253-66. https://doi.org/10.1007/s40258-020-00615-3.

5. The Royal New Zealand College of General Practitioners. Royal NZ College GP Workforce Survey Report 2018. July 2019. Available from: https://www. rnzcgp.org.nz/RNZCGP/Publications/The_GP_workforce/RNZCGP/Publica tions/GP_workforce.aspx?hkey=a7341975-3f92-4d84-98ec-8c72f7c8e151. Accessē Oct 2019.

6. Carswell S, Donovan E, Pimm F. Equitable access to medicines via primary healthcare -a review of the literature. PHARMAC. September 2018. Available from: https://www.pharmac.govt.nz/assets/equitable-access-to-medicinesliterature-review.pdf. Accessed 10 Apr 2020.

7. Raghunandan R, Tordoff J, Smith A. Non-medical prescribing in New Zealand: an overview of prescribing rights, service delivery models and training. Ther Adv Drug Saf. 2017;8(11):349-60. https://doi.org/10.1177/2042 098617723312.

8. Smith A. Non-medical prescribing in New Zealand: is it achieving its aims? Int J Integr Care. 2017:17(3):A31. https://doi.org/10.5334/ijic.3143.

9. Pirret AM. A critical care nurse practitioner's prescribing using standing orders and authorised prescribing when performing a critical care outreach role: a clinical audit. Intensive Crit Care Nurs. 2012;28(1):1-5. https://doi. org/10.1016/j.iccn.2011.10.008.

10. Poot B, Zonneveld R, Nelson K, Weatherall M. Prescribing by nurse practitioners: insights from a New Zealand study. J Am Assoc Nurse Pract. 2017;29(10):581-90. https://doi.org/10.1002/2327-6924.12493. 
11. Poot B, Nelson K, Zonneveld R, Weatherall M. Potentially inappropriate medicine prescribing by nurse practitioners in New Zealand. J Am Assoc Nurse Pract. 2020;32(3):220-8. https://doi.org/10.1097/jxx.0000000000000239.

12. Ponnambalam $Y$, Love $R$, Thomson M. Bacterial chemoprophylaxis knowledge and practice among New Zealand dentists. N Z Dent J. 2007; 103(3):51-7.

13. Ministry of Health NZ. Pharmaceutical Collection data 1 Jan 2016-30 June 2020 [data extracted February_March 2020]. Available from: https://www. health.govt.nz/nz-health-statistics/national-collections-and-surveys/ collections/pharmaceutical-collection

14. Ministry of Health NZ. Primary Health Organisation Enrolment Collection 1 January 2016-30 June 2020 [data extracted February_March 2020]. Available from: https://www.health.govt.nz/nz-health-statistics/nationalcollections-and-surveys/collections/primary-health-organisation-enrolmentcollection.

15. Ministry of Health NZ. Access to Primary Care Data Set. April 2020. Available from: https://www.health.govt.nz/system/files/documents/pages/2020q2primary-care-tier-1-statistics.xlsx.

16. PHARMAC. About the Schedule. 16 June 2020. https://pharmac.govt.nz/pha rmaceutical-schedule/inside-the-pharmaceutical-schedule/. Accessed 2 Nov 2020.

17. PHARMAC. Our place in the health system. 26 August 2020. https://pharma c.govt.nz/about/what-we-do/our-place-in-the-health-system/. Accessed 2 Nov 2020.

18. PHARMAC. An introduction to PHARMAC. 26 August 2020. https://pharmac. govt.nz/about/what-we-do/welcome-to-pharmac/. Accessed 2 Nov 2020.

19. Ministry of Health NZ. Pharmaceutical Collection. 26 September 2019. https://www.health.govt.nz/nz-health-statistics/national-collections-andsurveys/collections/pharmaceutical-collection. Accessed 2 Nov 2020.

20. Ministry of Health NZ. Primary Health Organisation Enrolment Collection. 22 July 2019. https://www.health.govt.nz/nz-health-statistics/nationalcollections-and-surveys/collections/primary-health-organisation-enrolmentcollection. Accessed 1 Nov 2020.

21. Atkinson J, Salmond C, Crampton P. NZDep2013 index of deprivation. Dunedin: University of Otago. 2014. Available from: https://www.otago.ac. nz/wellington/otago069936.pdf. Accessed 2 Oct 2020.

22. Moore D, Blick G, Whelan C. Report prepared for the Ministry of Health: review of the rural and tertiary adjusters. Wellington: Sapere2015. Accessed 28 Nov 2020.

23. Nursing Council of New Zealand. Registered nurse prescribing. October 2020. https://www.nursingcouncil.org.nz/Public/Nursing/Nurse_prescribing/ NCNZ/nursing-section/Nurse_Prescribing.aspx?hkey=091ed930-56ca-4f25-a e9e-52b33decb227. Accessed Oct 2020.

24. Nursing Council of New Zealand. The Nursing Council of New Zealand Annual Report 2019. Available from: https://www.nursingcouncil.org.nz/Public/Publica tions/Annual_report/NCNZ/publications-section/Annual_reports.aspx?hkey= 8e07d135-7e88-4024-9a2e-4d55e2900eef. Accessed Jul 2020.

25. Statistics New Zealand. Ethnic group summaries reveal New Zealand's multicultural make-up. 3 September 2020. https://www.stats.govt.nz/news/ ethnic-group-summaries-reveal-new-zealands-multicultural-make-up Accessed 1 Nov 2020.

26. Statistics New Zealand. New Zealand 2018 Census Population Counts 2020. https://www.stats.govt.nz/tools/2018-census-place-summaries/new-zeala nd\#population-counts. Accessed 1 Nov 2020.

27. Best Practice Advocacy Centre (BPAC) New Zealand. Sample General Practitioner Annual Prescribing Report.2018. Available from: https://bpac.org. nz/report/2018/AnnualReport2018_SampleGPReport.pdf. Accessed 9 Nov 2020.

28. Best Practice Advocacy Centre (BPAC) New Zealand. Analgesic update-2018. 29 March 2018. https://bpac.org.nz/report/snippet/analgesic-update.aspx. Accessed 10 Nov 2020.

29. Courtenay M, Gillespie D, Lim R. Patterns of dispensed non-medical prescriber prescriptions for antibiotics in primary care across England: a retrospective analysis. J Antimicrob Chemother. 2017;72(10):2915-20. https://doi.org/10.1093/jac/dkx230.

30. Nursing and Midwifery Council UK. Standards for prescribing programmes. 2020. https://www.nmc.org.uk/standards/standards-for-post-registration/sta ndards-for-prescribers/standards-for-prescribing-programmes/. Accessed 7 Nov 2020.

31. Teoh L, Marino RJ, Stewart K, McCullough MJ. A survey of prescribing practices by general dentists in Australia. BMC Oral Health. 2019;19(1):193. https://doi.org/10.1186/s12903-019-0882-6.
32. Ministry of Health NZ. Wai 2575 Māori Health Trends Report. Wellington: Ministry of Health. 2019. Available from: https://www.health.govt.nz/publica tion/wai-2575-maori-health-trends-report. Accessed 10 Nov 2020.

33. Statistics New Zealand and Ministry of Pacific Island Affairs. Health and Pacific peoples in New Zealand. Wellington, New Zealand2011. Available from: https://www.stats.govt.nz/assets/Uploads/Reports/Health-and-PacificPeoples-in-New-Zealand/Health-and-Pacific-Peoples-in-New-ZealandOctober-2011.pdf. Accessed 10 Nov 2020.

34. New Zealand Doctor. Unanimous backing for NZ rural health commissioner to relieve crisis in rural health. 8 November 2019. https://www.nzdoctor.co. nz/article/undoctored/unanimous-backing-nz-rural-health-commissionerrelieve-crisis-rural-health. Accessed 10 Nov 2020.

35. Ministry of Health NZ. Regional Data Explorer 2014-17: New Zealand Health Survey [ Experienced one or more types of unmet need for primary health care in the past 12 months by DHB]. 2018. Available from: https://minhea Ithnz.shinyapps.io/nz-health-survey-2014-17-regional-update.

36. Graham-Clarke E, Rushton A, Noblet T, Marriott J. Non-medical prescribing in the United Kingdom National Health Service: A systematic policy review. PLoS One. 2019;14(7):e0214630-e. doi:https://doi.org/10.1371/journal.pone. 0214630 .

37. Hindi AMK, Seston EM, Bell D, Steinke D, Willis S, Schafheutle El. Independent prescribing in primary care: a survey of patients', prescribers' and colleagues' perceptions and experiences. Health \& Social Care Community. 2019;27(4):e459-e70. https://doi.org/10.1111/hsc.12746.

38. Latter S, Blenkinsopp A, Smith A, Chapman S, Tinelli M, Gerard K et al. Evaluation of nurse and pharmacist independent prescribing. University of Southampton; Keele University, Department of Health Policy. 2010.

39. lacobucci G. Pharmacists delivered $60 \%$ more flu vaccines through NHS scheme last winter, figures show. BMJ. 2017;359:j5350. https://doi.org/10.113 6/bmj.j5350.

40. Isenor JE, Bowles SK. Opportunities for pharmacists to recommend and administer routine vaccines. Can Pharm J (Ott). 2019;152(6):401-5. https:// doi.org/10.1177/1715163519878473

41. Ministry of Health NZ. DHB spending on services for older people. 13 July 2016. https://www.health.govt.nz/nz-health-statistics/health-statistics-and-da ta-sets/older-peoples-health-data-and-stats/dhb-spending-services-olderpeople. Accessed 10 Nov 2020.

42. Marra C, Johnston K, Santschi V, Tsuyuki RT. Cost-effectiveness of pharmacist care for managing hypertension in Canada. Can Pharm J (Ott). 2017;150(3): 184-97. https://doi.org/10.1177/1715163517701109.

43. Al Hamarneh YN, Johnston K, Marra CA, Tsuyuki RT. Pharmacist prescribing and care improves cardiovascular risk, but is it cost-effective? A costeffectiveness analysis of the R(x) EACH study. Can Pharm J (Ott). 2019;152(4): 257-66. https://doi.org/10.1177/1715163519851822.

44. Ministry of Health NZ. Together we can keep antibiotics working: for community-based health services. 2 September 2020. https://www.health. govt.nz/our-work/diseases-and-conditions/antimicrobial-resistance/togetherwe-can-keep-antibiotics-working/together-we-can-keep-antibiotics-workingcommunity-based-health-services. Accessed 18 Nov 2020.

45. Whyler N, Tomlin A, Tilyard M, Thomas M. Ethnic disparities in community antibacterial dispensing in New Zealand, 2015. N Z Med J. 2018;131(1480): 50-60.

46. Costelloe C, Metcalfe C, Lovering A, Mant D, Hay AD. Effect of antibiotic prescribing in primary care on antimicrobial resistance in individual patients: systematic review and meta-analysis. BMJ. 2010;340(may18 2):c2096. https:// doi.org/10.1136/bmj.c2096.

47. Glasziou P, Del Mar C, Rovers M. Antibiotics and acute otitis Media in Children. JAMA. 2011;305(10):997-8. https://doi.org/10.1001/jama.2011.240.

48. World Health Organization. Antimicrobial resistance. 13 October 2020. https://www.who.int/news-room/fact-sheets/detail/antimicrobial-resistance. Accessed 10 Nov 2020.

49. Goossens $H$, Ferech M, Vander Stichele R, Elseviers M. Outpatient antibiotic use in Europe and association with resistance: a cross-national database study. Lancet. 2005;365(9459):579-87. https://doi.org/10.1016/S0140-673 6(05)17907-0.

50. World Health Organization. Antibiotic resistance. 31 July 2020. https://www. who.int/news-room/fact-sheets/detail/antibiotic-resistance. Accessed $10 \mathrm{Nov}$ 2020.

51. Kim B, Nolan S, Beaulieu T, Shalansky S, Ti L. Inappropriate opioid prescribing practices: a narrative review. Am J Health Syst Pharm. 2019; 76(16):1231-7. https://doi.org/10.1093/ajhp/zxz092. 
52. Best Practice Advocacy Centre (BPAC) New Zealand. Prescribing tramadol appropriately. 23 February 2018. https://bpac.org.nz/2018/tramadol.aspx. Accessed 10 Nov 2020

53. Blanch B, Pearson S-A, Haber PS. An overview of the patterns of prescription opioid use, costs and related harms in Australia. Br J Clin Pharmacol. 2014; 78(5):1159-66. https://doi.org/10.1111/bcp.12446.

54. Vojtila L, Pang M, Goldman B, Kurdyak P, Fischer B. Non-medical opioid use, harms, and interventions in Canada - a 10-year update on an

unprecedented substance use-related public health crisis. Drugs: Education, Prevention and Policy. 2020;27(2):118-22. https://doi.org/10.1080/09687637.2 019.1645094.

\section{Publisher's Note}

Springer Nature remains neutral with regard to jurisdictional claims in published maps and institutional affiliations.

Ready to submit your research? Choose BMC and benefit from:

- fast, convenient online submission

- thorough peer review by experienced researchers in your field

- rapid publication on acceptance

- support for research data, including large and complex data types

- gold Open Access which fosters wider collaboration and increased citations

- maximum visibility for your research: over $100 \mathrm{M}$ website views per year

At BMC, research is always in progress.

Learn more biomedcentral.com/submissions 